\title{
Meeting warms to binding climate agreement
}

London. An international law penalizing countries that fail to meet agreed targets for reducing greenhouse gas emissions edged a step closer to reality last week after a meeting in Geneva of representatives of countries that have signed the climate change convention.

The United Nations Framework Convention on Climate Change, agreed at the Earth Summit in Rio de Janeiro in 1992, recommends - but does not legally bind - developed countries to reduce greenhouse gas emissions to 1990 levels by 2000 .

Although some countries have already begun to implement policies designed to achieve this goal, many others, including some of the largest emitters such as the United States, have made little progress.

Now many signatories to the convention - including the United States, China and the European Union - have agreed on the need for a legal instrument to ensure that countries comply with future targets to reduce emissions of greenhouse gases.

Both the proposed new agreement and the question of specific targets for emission reductions are expected to be finalized by the third annual conference of the climate convention to be held, possibly in Tokyo (see below), late next year.

There are two broad options for the new law. The European Union and the Alliance of Small Island States (AoSIS) are backing a protocol - a legally binding treaty - to regulate greenhouse gas emissions that would be independent of the climate convention.

Such an approach would mirror that of the Montreal Protocol banning ozone depleting substances, often cited as an example of a successful protocol that broke off from its 'mother' convention - the Vienna Convention on the protection of the ozone layer.

But this approach is not unanimously favoured. US delegates in particular, while stating that "the United States is not opposed to a protocol per se", emphasized the advantages of amending the existing climate convention rather than enacting a new treaty requiring fresh signatures and a new set of associated institutions.

Whatever form the new legal instrument takes, some countries, such as Japan and Canada, warned last week that it was premature to discuss the choice of an instrument without first outlining its substance.

AoSIS - some of whose states risk severe flooding if sea levels continue to rise - want a protocol that binds countries to reduce greenhouse gas emissions by 20 per cent by the year 2005. Russia, in contrast, while agreeing on the need for a protocol, argues that targets for emission reductions should reflect a country's economic health.

The outcome of the debate will also be directly affected by the absence within the climate convention of an agreed decisionmaking procedure for a protocol.

The enactment of any legal instrument would have to pass through two stages adoption by member countries meeting at a climate conference, followed by ratification in national parliaments.

An amendment to the climate convention needs ratification by three-quarters of the member countries. A protocol, however, would be more difficult to secure, as the convention does not set out rules for adopting or ratifying a protocol. In the absence of such rules, a decision on a protocol will like other issues in the climate convention - need the consent of all parties.

Forging any such consensus, however, is controversial, particularly, among environmentalists. The Climate Action Network (CAN), an alliance of groups that includes Greenpeace, the World Wide Fund for Nature and the Natural Resources Defense Council, would like member countries to resort to majority voting, as this would prevent small, vocal minorities from blocking the implementation of particular measures.

\section{Japan cools conference offer for 1997}

London. The location of next year's third annual meeting of the climate convention has been thrown into unexpected doubt by an announcement by Japan's delegation last week in Geneva (see above) that it was having second thoughts about hosting the meeting.

Last year, Japan announced an official "expression of interest" in hosting the 1997 conference, a move that was regarded by many as virtually a clear offer. It was seen as a potentially significant move for the meeting to take place in a country where environmental issues have not always been a high priority.

A short-list of seven cities - includ- ing Tokyo, Yokohama, Kyoto and Kobe had been drawn up, and a final choice was believed to be imminent. Last week, however, Japanese officials announced that no decision had been reached on hosting the conference in Japan, although they promised that such a decision would be made in two months.

"Japan needs time to discuss this issue," says Kenji Kamigawara, a member of the delegation and first secretary to Japan's mission in Geneva. Kamigawara says that any such decision will need the approval of Japan's cabinet. "We also need to ask the finance ministry to release funds." $\quad$ E. M.

\section{IMAGE \\ UNAVAILABLE FOR COPYRIGHT REASONS}

Clearing the way? A new climate protocol would require extensive groundwork.

"When consensus fails, the parties must have some mechanism for breaking a deadlock," says an article in Eco, the CAN newsletter. "No state should possess a veto over efforts to protect the global commons."

Legal experts point out that governments could choose to make decisions by majority vote, but add that this is unlikely to happen. Patrick Széll, legal adviser to the UK delegation to the climate conference, points out that, under the convention, members can call a vote "as a last resort if all efforts to reach a consensus have been exhausted".

Similarly, under the Vienna Convention on the Law of Treaties, a decision can be made by a two-thirds majority vote if a treaty's existing rules do not specify a decision-making method. But Széll points out that major states - such as the United States, China, Saudi Arabia and Venezuela - are not parties to the Vienna convention.

Governments - regardless of their views on the measures needed to stabilize greenhouse gases in the atmosphere - have held back from calling a vote on any specific issue. Mohammad Al-Sabban, Saudi Arabia's delegate to the climate conference, says that majority voting may alienate minority countries, which could weaken a treaty.

Tuiloma Neroni Slade, Samoa's representative to the United Nations and a member of the AoSIS delegation, agrees. "I'd rather not put [decisions] to the vote," he says. "Climate change is a global issue. We must solve it together."

Indeed, many developed countries, which bear most of the costs of the climate convention, appear to be opposed in private to majority voting. "The donor countries want to guard against the theoretical possibility of losing an important vote to a coalition of the smaller and developing countries," says one government lawyer.

Ehsan Masood 